LUNG CANCER

\title{
Lung cancer in Teesside (UK) and Varese (ltaly): a comparison of management and survival
}

\author{
A Imperatori, R N Harrison, D N Leitch, F Rovera, G Lepore, G Dionigi, P Sutton, \\ L Dominioni
}

See end of article for authors' affiliations

Correspondence to

Dr A Imperatori, Center for

Thoracic Surgery,

University of Insubria,

Ospedale di Circolo, Viale

Borri 57, 21100 Varese,

Italy; andrea.imperatori@

uninsubria.it

Received 20 April 2005

Accepted 26 October 2005

Published Online First

11 November 2005
Background: The survival of lung cancer patients in the UK is lower than in other similar European countries. The reasons for this are unclear.

Methods: Two areas were selected with a similar incidence of lung cancer: Teesside in Northern England and Varese in Northern Italy. Data were collected prospectively on all new cases of lung cancer diagnosed in the year 2000. Comparisons were made of basic demographic characteristics, management, and survival.

Results: There were 268 cases of lung cancer in Teesside and 243 in Varese. Patients in Teesside were older ( $p<0.05)$, were more likely to have smoked ( $<<0.001)$, had a higher occupational risk $(p<0.001)$, higher co-morbidity $(p<0.05)$, and poorer performance status $(p<0.001)$. Fewer patients in Teesside presented as an incidental finding $(p<0.001)$ and the histological confirmation rate was lower than in Varese $(p<0.01)$. In Teesside there were more large cell carcinomas $(p<0.001)$, more small cell carcinomas $(p<0.05)$, and fewer early stage non-small cell lung cancers $(p<0.05)$. The resection rate was lower in Teesside (7\% v 24\%; $p<0.01)$ and more patients received no specific anti-cancer treatment $(50 \%$ $v 25 \% ; \mathrm{p}<0.001)$. Overall 3 year survival was lower in Teesside (7\% v 14\%; $<<0.001)$. Surgical resection was the strongest multivariate survival predictor in Varese $(H R=0.46)$ and Teesside $(H R=0.31)$. Comorbidity in Teesside resulted in a significantly lower resection rate $(p<0.001)$.

Conclusions: Patients with lung cancer in Teesside presented at a later stage, with more aggressive types of tumour, and had higher co-morbidity than patients in Varese. As a result, the resection rate was significantly lower and survival was worse.
$\mathrm{F}$ ive year survival rates for lung cancer in the UK are quoted as $5-6 \%$ compared with rates of $8-15 \%$ in other European countries and the USA. ${ }^{1-4}$ There are several possible explanations, including differences in demography, in tumour biology, in co-morbidity and-more controversially-differences in management, particularly in resection rates. Overall the resection rates in the UK are quoted as 10\% or less, ${ }^{56}$ whereas in other European countries and in the US the rates are said to be more than $20 \% .{ }^{47}$ Differences in the ways in which data were collected and the resection rates expressed make comparisons between studies difficult, and some authors have argued that the differences in survival reflect methodological bias rather than a true difference in the disease or its management. ${ }^{8}$ Moreover, few if any prospective studies have synchronously evaluated management of lung cancer in the UK and in another European country.

The aim of this study is to compare lung cancer management and survival in two areas: one in Northern England (Teesside) and one in Northern Italy (Varese) with a similar incidence of lung cancer but, historically, with different resection rates. Moreover, in the year 2000 Varese had a voluntary chest radiography screening programme for lung cancer, covering about $10 \%$ of smokers at risk in the population in the Varese area. ${ }^{9}$ Both sites have a well established lung cancer register and we were confident of collecting thorough and accurate data.

\section{METHODS}

\section{Data collection}

Data were collected prospectively on all new cases of lung cancer diagnosed in the year 2000 and comparisons were made of basic demographic characteristics, management and survival. Clinical details and management data were collected from the hospital records of all patients presenting in Teesside and in Varese from 1 January 2000 to 31 December 2000 with a new clinical or pathological diagnosis of lung cancer (ICD-10 C33-C34). Cases of mesothelioma, carcinoid, adenocystic carcinoma, and adenosquamous carcinoma of the lung were excluded. The referral hospitals in Teesside were University Hospital of North Tees, Stockton, and University Hospital of Hartlepool serving a population of about 320 000, and University of Insubria Azienda Ospedale di Circolo di Varese and the Azienda Ospedale S Antonio Abate di Gallarate in Varese serving a population of about 350000 .

The two hospitals in the UK are medium sized district general hospitals at which chemotherapy is administered. Surgery and radiotherapy are performed after referral to the sub-regional centre in Middlesbrough. In Varese, surgery for all the hospitals is performed at the sub-regional Center for Thoracic Surgery of the University of Insubria and radiotherapy is performed at the Ospedale di Circolo. Chemotherapy is administered at both hospitals.

In the two UK hospitals all outpatients and inpatients with suspected lung cancer are referred to the respiratory physicians for an opinion; in the two Italian hospitals the initial referral may be to the respiratory physicians, to the thoracic surgeons, or to the oncologists.

Patients presenting with suspected lung cancer in both Teesside and Varese were investigated using similar protocols

Abbreviations: NSCLC, non-small cell lung cancer; SCLC, small cell lung cancer 
consistent with the BTS guidelines. ${ }^{10}$ An identical database was used for the two populations. Acknowledging previous concerns about the completeness of data collection, there was a particular emphasis on capturing all new cases during the year 2000. The case notes were identified by Clinical Effectiveness coordinators and the relevant data extracted. All records were then reviewed by a clinical member of the team to ensure the validity and accuracy of the data collection under the supervision of the principal investigators.

Local research ethics committee approval was obtained on both UK and Italian sites.

\section{Diagnosis and management}

Conventional diagnostic and staging procedures were followed using bronchoscopy, computed tomographic (CT) scanning of the chest, fine needle aspiration cytology (FNAC) and, in a few selected cases, mediastinoscopy. ${ }^{11}$

Management was broadly in line with the BTS recommendations ${ }^{10}$-namely, surgical resection for suitable patients with early stage non-small cell lung cancer (NSCLC stages I and II) and, in Varese, for a selected group of low risk stage IIIA; radical radiotherapy ( $\geqslant 50 \mathrm{~Gy}$ ) for early stage NSCLC not eligible for surgery; chemotherapy and/or radiotherapy for good performance status patients with inoperable NSCLC (stages III and IV); chemotherapy with or without radiotherapy for small cell lung cancer (SCLC). Palliative treatment comprised local radiotherapy (single fraction or low dose), pain control, nutritional support, and chemotherapy. Management decisions in both sites were based on discussions at multidisciplinary team meetings.

\section{Data recorded}

The following data were extracted from the case records: age at diagnosis; sex; risk factors (smoking habit, occupational risk, family history of lung cancer); co-morbidities; percentage predicted forced expiratory volume in 1 second $\left(\mathrm{FEV}_{1}\right)$; performance status according to WHO-ECOG; source of referral to lung cancer specialist; mode of presentation; clinical diagnosis or histological subtype; clinical stage; management: no active cancer treatment/treatment (surgery, chemotherapy, radiotherapy); and causes for non-operability (histology, stage, co-morbidity).

There were no assessments of either socioeconomic status or of delays and time intervals in the course of the patients' care.

The survival status of all patients was recorded and updated every 6 months until death or until 3 years had elapsed after the enrolment of the last patient; this allowed for the maturation of survival data and for quality control.

\section{Definitions used in the study}

Date of diagnosis: defined, in order of priority, as the date of histological confirmation or cytological confirmation, or diagnostic radiology. ${ }^{12}$

Occupational risk: occupations and industries that are known (list A) or suspected (list B) to be associated with lung cancer. ${ }^{13}$

Co-morbidity: the presence of an illness which would normally be recorded on a death certificate; the decision was made by the clinician reviewing the notes.

Source of referral: from a general practitioner or from another consultant or (Varese) from the chest radiography screening programme.

Urgent/emergency admission: an admission made at short notice at the request of accident and emergency services, general practitioners, bed bureaux, or consultant outpatient clinic. ${ }^{14}$

Lung cancer specialist: respiratory physician, thoracic surgeon, oncologist, or radiotherapist.
Tumour staging: only the clinical stage, routinely obtained in all NSCLC patients according to the Mountain system, ${ }^{15}$ is reported and used for comparison of the results. Because of the low resection rates, the overall number of pathologically staged cancers in Teesside and Varese was very small and did not allow meaningful stratification and analysis by pathological stage.

Active treatment: any specific anti-cancer treatment (surgery, chemotherapy, radiotherapy) within 6 months of diagnosis.

Resection rate: the proportion, expressed as a percentage of all cases (clinical diagnosis and pathological diagnosis), where an operation was performed to eradicate the cancer.

Survival was calculated from the day of pathological diagnosis of lung cancer or the day when the patient was informed about the clinical diagnosis to death.

\section{Analysis of results and statistical methods}

The significance of any difference in the characteristics of the lung cancer patients between the Teesside and Varese cohorts was evaluated. Where differences were found, Cox's proportional hazard regression (univariate and multivariate analysis) was used to identify independent predictors of death during the 3 years following diagnosis.

Data were expressed as mean with standard deviation (SD) or median and range according to the data distribution. The Student's $t$ test was used for analysis of continuous data and the $\chi^{2}$ test was used to compare differences between proportions. The Mann-Whitney U test was used to compare median values. Survival rates were calculated using the Kaplan-Meier method and the log rank test was used to compare survival rates. Cox's proportional hazards regression was used to model lung cancer death among cases and hazard ratios (HR) and $\mathrm{p}$ values were calculated; $\mathrm{p}$ values $<0.05$ were considered significant.

SPSS Version 11.0 (MapInfo Corporation, Troy, NY, USA) was used for data analysis.

\section{RESULTS \\ Patient characteristics}

The case records of 273 patients in Teesside and 251 in Varese presenting with probable lung cancer between 1 January and 31 December 2000 were reviewed. Five patients in Teesside and eight in Varese were excluded on the basis of histology (carcinoid, adenocystic, adenosquamous). The final totals were therefore 268 in Teesside and 243 in Varese, representing an annual incidence of 85 and 72 per 100000 population respectively.

Table 1 shows the demographic data, risk factors, comorbidity, performance status, source of referral, and mode of presentation of the two cohorts. In the Teesside cohort the mean age was higher $(69(10) v 67(10)$ years; $p=0.032)$ and there were more women $(\mathrm{p}<0.001)$ than in the Varese cohort.

The prevalence of current smokers and former smokers was significantly higher in the Teesside cohort $(\mathrm{p}<0.001)$ but the median pack-years of cigarette smoking was not significantly different $(p=0.659$, Mann-Whitney $U$ test $)$. The high rate of never smokers in Varese is mainly the result of a significantly higher prevalence of never smokers in Varese women (53\%) than in Teesside women $(6 \%$; $\mathrm{p}<0.001)$. The prevalence of never smokers among the men was similar in Varese and Teesside $(5 \% v 2 \% ; \mathrm{p}=0.13)$.

Occupational risk was significantly more prevalent in Teesside patients $(\mathrm{p}<0.001)$, while the rate of family history of lung cancer did not differ ( $13 \% v 15 \% ; \mathrm{p}=0.578)$. In the Teesside cohort the rate of co-morbidity was significantly higher $(p=0.026)$. Patients in this cohort with co-morbidity had a mean of 1.58 conditions (41\% cardiovascular, $31 \%$ COPD, $8 \%$ diabetes or other metabolic diseases, $20 \%$ 


\begin{tabular}{|c|c|c|c|}
\hline & $\begin{array}{l}\text { Teesside } \\
(n=268)\end{array}$ & $\begin{array}{l}\text { Varese } \\
(n=243)\end{array}$ & p value \\
\hline Mean (SD) age (years) & $69(10)$ & $67(10)$ & 0.032 \\
\hline$M / F$ (ratio) & $153 / 115(1.33)$ & $200 / 43(4.65)$ & $<0.001$ \\
\hline \multicolumn{4}{|l|}{ Risk factors } \\
\hline Smoker (\%) & $142 / 257(55 \%) \dagger$ & $111 / 243(46 \%)$ & \\
\hline Former smoker (\%) & $105 / 257(41 \%) \dagger$ & $99 / 243(41 \%)$ & $<0.001$ \\
\hline Never smoker (\%) & $10 / 257(4 \%) \dagger$ & $33 / 243(13 \%)$ & \\
\hline Median pack years§§§ & $45.5 \ddagger$ & $45.0 \S$ & 0.659 ल9 \\
\hline Occupational risk (\%)* & $93 / 185(50 \%)$ & $69 / 226(31 \%)^{* *}$ & $<0.001$ \\
\hline Family history of lung cancer & $20 / 149(13 \%)+\dagger$ & $37 / 239(15 \%) \neq \ddagger$ & 0.578 \\
\hline No of patients with co-morbidity (\%) & $193 / 263(73 \%) \S \S$ & $156 / 243(64 \%)$ & 0.026 \\
\hline Performance status $0-1$ & $38 \%$ & $62 \%$ & $<0.001$ \\
\hline Performance status $2-4$ & $62 \%$ & $38 \%$ & \\
\hline $\mathrm{FEV}_{1}(\%$ predicted) & $63 \%(22) \oplus$ & $78 \%(23)^{\star \star \star}$ & $<0.001$ \\
\hline \multicolumn{4}{|l|}{$\begin{array}{l}\text { Source of referral to lung cancer } \\
\text { specialist }\end{array}$} \\
\hline GP, urgent/emergency & $64 \%$ & $61 \%$ & 0.502 \\
\hline GP, routine & $20 \%$ & $14 \%$ & 0.108 \\
\hline Other consultant & $16 \%$ & $23 \%$ & 0.076 \\
\hline Chest radiography screening & $0 \%$ & $2 \%$ & 0.018 \\
\hline \multicolumn{4}{|l|}{ Mode of presentation } \\
\hline $\begin{array}{l}\text { Asymptomatic diagnosis by chest } \\
\text { radiography }\end{array}$ & 17/253 (7\%)††† & $47 / 223(21 \%) \neq \neq \ddagger$ & \\
\hline Diagnosis by symptoms & 236/253 (93\%)+†† & 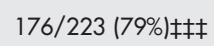 & \\
\hline \multicolumn{4}{|c|}{ 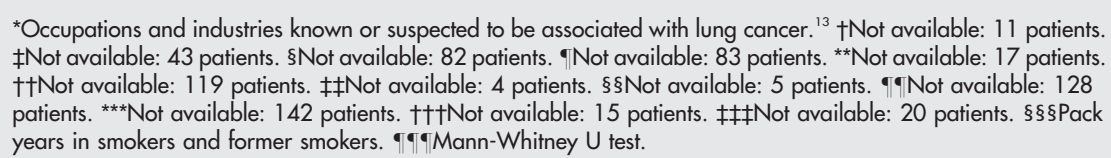 } \\
\hline
\end{tabular}

miscellaneous). Patients with co-morbidity in the Varese cohort had a mean of 1.43 conditions (34\% cardiovascular, $30 \%$ COPD, $12 \%$ diabetes or other metabolic diseases, $24 \%$ miscellaneous). In Teesside patients the mean (SD) $\mathrm{FEV}_{1}$ was $63(22) \%$ predicted, significantly lower than in the patients in Varese $(78(23) \%$ predicted; $\mathrm{p}<0.001)$. The UK cohort had a significantly poorer performance status $(p<0.001$, table 1$)$.

The referral patterns were similar in the two sites. Referral by general practitioners was slightly less frequent in Varese while referral by other consultant specialists was more frequent. In Varese the chest radiography screening programme yielded $2 \%$ of the referrals. Lung cancer was asymptomatic in $7 \%$ of the UK patients, a significantly lower rate than in Varese $(21 \% ; \mathrm{p}<0.001$, table 1$)$.

The histological confirmation rate was lower in Teesside than in Varese $(72 \% v 82 \%, \mathrm{p}<0.01$; table 2$)$. The prevalence of large cell carcinoma $(p<0.001)$ and of SCLC $(p=0.028)$ was significantly higher in Teesside than in Varese.

In Teesside the proportion of all NSCLC (adenocarcinoma, squamous cell carcinoma, large cell carcinoma, and unspecified NSCLC) was significantly lower than in Varese $(55 \% \mathrm{v}$ $70 \%, \mathrm{p}<0.001)$. There was a lower proportion of early NSCLC (stage I-II) among all Teesside patients ( $14 \% \vee 22 \%$, $\mathrm{p}=0.018)$, but six patients with NSCLC in Teesside were not staged due to severe co-morbidity while in Varese all NSCLCs were staged $(\mathrm{p}=0.019)$.

\section{Modalities of treatment}

The surgical resection rate was significantly higher in Varese than in Teesside $(p<0.001$, table 3$)$. There were no deaths during the 30 days after surgery in Teesside while in Varese one of 59 patients (1.7\%) died following surgery. No

\begin{tabular}{|c|c|c|c|}
\hline & $\begin{array}{l}\text { Teesside } \\
(\mathrm{n}=268)\end{array}$ & $\begin{array}{l}\text { Varese } \\
(n=243)\end{array}$ & $p$ value \\
\hline Histologically unconfirmed cases & $75(28 \%)$ & $44(18 \%)$ & $<0.01$ \\
\hline Histologically confirmed cases & $193(72 \%)$ & $199(82 \%)$ & $<0.01$ \\
\hline NSCLC & $147(55 \%)$ & $169(70 \%)$ & $<0.001$ \\
\hline Adenocarcinoma & $42(22 \%)^{*}$ & $60(30 \%)^{*}$ & 0.058 \\
\hline Squamous cell carcinoma & $68(35 \%)^{*}$ & $84(42 \%)^{*}$ & 0.156 \\
\hline Large cell carcinoma & $21(11 \%)^{*}$ & $4(2 \%)^{*}$ & $<0.001$ \\
\hline Unspecified NSCLC & $16(8 \%)^{*}$ & $21(11 \%)^{*}$ & 0.446 \\
\hline $\mathrm{SCLC}$ & $46(24 \%)^{*}$ & $30(15 \%)^{*}$ & 0.028 \\
\hline \multicolumn{4}{|l|}{ NSCLC by clinical stage } \\
\hline Stage I-II & $37(14 \%)$ & $53(22 \%)$ & 0.018 \\
\hline Stage III-IV & $104(39 \%)$ & $116(48 \%)$ & 0.042 \\
\hline $\begin{array}{l}\text { NSCLC not staged due to severe co- } \\
\text { morbidity }\end{array}$ & $6(2 \%)$ & $0(0 \%)$ & 0.019 \\
\hline $\begin{array}{l}\text { SCLC, small cell lung cancer; NSCLC, } \\
\text { carcinoma, large cell carcinoma and } \\
\text { *Percentage of all histologically confirr }\end{array}$ & $\begin{array}{l}\text {-small cell } \\
\text { oecified NS }\end{array}$ & cluding ad & squamous cel \\
\hline
\end{tabular}


Table 3 Modalities of treatment of all lung cancers diagnosed in the year 2000 in Teesside and Varese

\begin{tabular}{|c|c|c|c|}
\hline & Teesside† & Varese & p value \\
\hline $\begin{array}{l}\text { Surgical resection§ } \\
\text { Radical radiotherapy ( } \geqslant 50 \mathrm{~Gy} \text { ) } \\
\text { Palliative radiotherapy } \\
\text { Chemotherapy } \\
\text { Radiotherapy + chemotherapy } \\
\text { No active cancer treatment }\end{array}$ & $\begin{array}{l}17(7 \%)^{*} \\
1(0.4 \%) \\
66(25 \%) \\
35(13 \%) \\
12(5 \%) \\
130(50 \%)\end{array}$ & $\begin{array}{l}59(24 \%) \\
2(0.8 \%) \\
54(22 \%) \\
45(19 \%) \\
23(9 \%) \\
60(25 \%)\end{array}$ & $\begin{array}{l}<0.001 \\
0.522 \\
0.420 \\
0.117 \\
0.032 \\
<0.001\end{array}$ \\
\hline \multicolumn{4}{|c|}{$\begin{array}{l}\text { Data are presented as number of patients with percentage of total valid cases. } \\
\text { *All } 17 \text { cases were NSCLC clinical stage I-II. } \\
\text { †Total valid cases in Teesside = } 261 / 268 \text {; the other seven patients moved to other districts and their treatment } \\
\text { could not be traced. } \\
\text { †Total valid cases in Varese = } 243 \text {. } \\
\text { §Resection rate of NSCLC clinical stage I-II was } 17 / 37 \text { (46\%) in Teesside and } 44 / 53(83 \%) \text { in Varese }(p<0.001) \text {. } \\
\text { Tlncluding } 44 \text { NSCLC stage I-II, } 8 \text { NSCLC stage III A, } 5 \text { NSCLC stage IIIB-IV (satellite nodule), and } 2 \text { SCLC (limited } \\
\text { disease). }\end{array}$} \\
\hline
\end{tabular}

explorative thoracotomies were performed in either cohort. Of all the patients presenting with NSCLC clinical stage I-II, the proportion resected was significantly higher in Varese than in Teesside ( $83 \% \vee 46 \%, \mathrm{p}<0.001)$. Moreover, in Varese resection was carried out in $8 / 20(40 \%)$ NSCLC clinical stage IIIA, whereas in Teesside none of 22 NSCLC clinical stage IIIA was resected $(p<0.001)$.

A similar proportion of patients in Teesside and in Varese received active cancer treatment with radical radiotherapy, palliative radiotherapy, or chemotherapy (table 3). In Teesside a significantly smaller proportion of patients received combination treatment with chemotherapy and radiotherapy $(p=0.032)$. Half of the patients in Teesside did not receive any active cancer treatment, a significantly greater proportion than in Varese $(\mathrm{p}<0.001)$.

\section{Survival}

Kaplan-Meier cumulative survival curves for patients in Teesside and Varese were significantly different $(p<0.001$, log rank test; fig 1) with median survival times markedly shorter in the UK cohort than in the Italian cohort $(3.6 \mathrm{v}$ 9.4 months). In the UK cohort $24 \%$ had died within 31 days or less from diagnosis compared with $7 \%$ in the Italian cohort. Overall survival at 1 and 3 years was 23\% and 7\% in Teesside and $39 \%$ and $14 \%$ in Varese.

Among all resected NSCLC clinical stage I-II patients (17 in Teesside and 44 in Varese), 3 year survival was 59\% in Teesside and $45 \%$ in Varese $(p=0.28, N S)$.

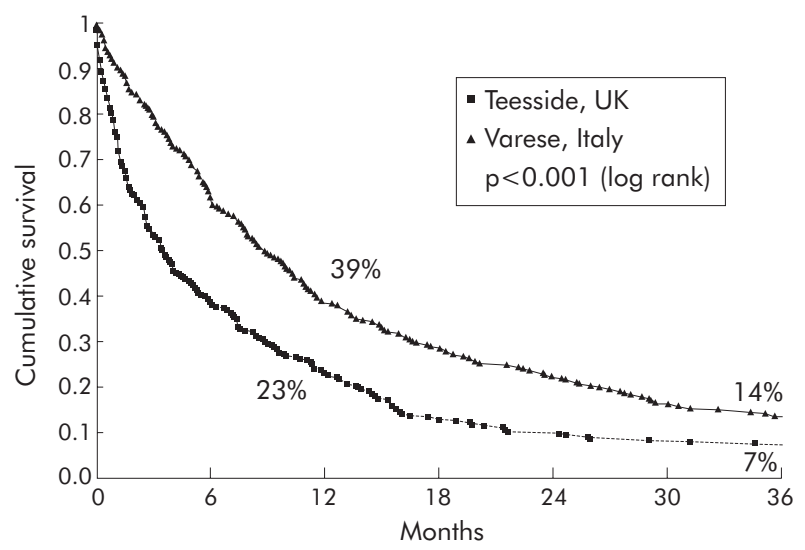

Figure 1 Kaplan-Meier survival (from diagnosis) of all patients presenting with lung cancer in the year 2000 in Teesside, UK $(n=268)$ and in Varese, Italy $(\mathrm{n}=243)$.

\section{Cox's proportional hazard regression}

Cox's proportional hazard regression relating patient characteristics to the risk of death within 3 years from diagnosis are shown in tables 4 and 5 .

Univariate analysis in the Teesside cohort (table 4) showed a significant decrease in the death HR when the following predictors were present: surgical resection $(\mathrm{p}<0.0001$; HR $0.14)$; NSCLC stage I-II, potentially operable by histology and stage $(\mathrm{p}<0.0001 ;$ HR 0.29); active cancer treatment $(\mathrm{p}<0.0001 ;$ HR 0.32); asymptomatic diagnosis $(\mathrm{p}=0.004$; HR 0.42); histology ( $\mathrm{p}=0.008$; HR 0.82); and, surprisingly, co-morbidity $(p=0.033$; HR 0.73$)$. The multivariate model for Teesside (table 4) includes co-morbidity, asymptomatic diagnosis, NSCLC stage I-II, active cancer treatment, surgical resection as predictor variables; histology was removed because of collinearity. Multivariate analysis showed that surgical resection $(p=0.01 ;$ HR 0.31$)$ and active cancer treatment $(p<0.0001$; HR 0.46$)$ are the only independent predictors of survival in the Teesside cohort.

Univariate analysis in the Varese cohort (table 5) showed that the mortality risk decreased with the predictors surgical resection $(\mathrm{p}<0.0001$; HR 0.27$)$; NSCLC stage I-II, potentially operable by histology and stage $(\mathrm{p}<0.0001$; HR 0.30$)$; asymptomatic diagnosis $(\mathrm{p}<0.0001$; HR 0.38$)$; active cancer treatment $(\mathrm{p}<0.0001$; HR 0.48); and histology ( $p=0.012$; HR $0.81)$. Multivariate predictors of survival in the Varese cohort were surgical resection $(\mathrm{p}=0.0016$; HR 0.46$)$ and asymptomatic diagnosis $(\mathrm{p}=0.045$; HR 0.65$)$.

The multivariate predictor with the lowest HR of death in Teesside and in Varese was surgical resection (tables 4 and $5)$. The main causes of non-operability in the two cohorts are shown in table 6 . The most frequent cause of non-operability was advanced stage NSCLC, which occurred at a similar rate in Teesside and Varese. SCLC histology resulted in nonoperability in a higher proportion of patients in Teesside than in Varese, but the difference was not significant $(p=0.053)$. Among all the other patients, co-morbidity was the main reason for non-resection and occurred in a significantly greater proportion of Teesside patients $(p<0.001)$. Importantly, the proportion of potentially operable NSCLC stage I-II that could not be resected due to co-morbidity was significantly greater in Teesside than in Varese (17/37 patients $(46 \%) \vee 9 / 53(17 \%) ; \mathrm{p}<0.01)$. Individual reasons for not operating on patients with NSCLC stage I-II in Teesside and in Varese are shown in table 7.

\section{DISCUSSION}

Previous studies comparing lung cancer in different institutions are difficult to interpret in terms of overall management and survival because of possible selection bias. ${ }^{8}$ It is evident 


\begin{tabular}{|c|c|c|c|}
\hline & p value§ & HR & $95 \% \mathrm{Cl}$ \\
\hline \multicolumn{4}{|l|}{ Univariate analysis } \\
\hline Age $(<65,65-75,75+$ years $) \dagger$ & 0.13 & 0.88 & 0.74 to 1.04 \\
\hline Sexł & 0.56 & 0.93 & 0.72 to 1.19 \\
\hline Smoking habit (yes, no) & 0.09 & 1.75 & 0.92 to 3.31 \\
\hline Occupational risk (yes, no) & 0.16 & 1.24 & 0.92 to 1.68 \\
\hline Co-morbidity (yes, no) & 0.033 & 0.73 & 0.55 to 0.97 \\
\hline Asymptomatic diagnosis (yes, no) & 0.004 & 0.42 & 0.24 to 0.76 \\
\hline Histology (NSCLC, SCLC, histologically unconfirmed lung cancer) & 0.008 & 0.82 & 0.72 to 0.95 \\
\hline NSCLC H-II (yes, no) & $<0.0001$ & 0.29 & 0.19 to 0.44 \\
\hline Active cancer treatment (yes, no) & $<0.0001$ & 0.32 & 0.28 to 0.46 \\
\hline Surgical resection (yes, no) & $<0.0001$ & 0.14 & 0.07 to 0.30 \\
\hline \multicolumn{4}{|l|}{ Multivariate analysis } \\
\hline Co-morbidity (yes, no) & 0.076 & 0.77 & 0.57 to 1.03 \\
\hline Asymptomatic diagnosis (yes, no) & 0.065 & 0.57 & 0.32 to 1.04 \\
\hline NSCLC I-II (yes, no) & 0.084 & 0.64 & 0.38 to 1.06 \\
\hline Active cancer treatment (yes, no) & $<0.0001$ & 0.46 & 0.35 to 0.60 \\
\hline Surgical resection (yes, no) & 0.01 & 0.31 & 0.13 to 0.75 \\
\hline
\end{tabular}

*Seven of the 268 Teesside patients were censored because they moved from the district and their treatment could not be traced.

†Age analysed as a trend through the three categories $(<65,65-75,75+$ years $)$.

‡Women $v$ men.

$\S p$ values for the predictors are the Wald statistics for the estimates in the model, conditional on the other predictors being present.

that a cohort which does not include cases too ill to undergo histological confirmation or who are clearly beyond active management will have better survival and higher resection rates than a cohort which is all inclusive. This is particularly the case for international comparisons because of differing referral patterns and pathways, and has been suggested as a reason why surgical rates and survival figures appear so poor in the UK. ${ }^{8}$ In this study we tried to avoid such problems in data collection by prospectively including all consecutive patients with lung cancer diagnosed in 2000, by using an identical database, and by the frequent exchange of information between the principal investigators.

The number of patients presenting with lung cancer in the year 2000 in Teesside $(n=268)$ and in Varese $(n=243)$ was similar to previous years in the same geographical areas. ${ }^{16-18}$ In 1995-9 the lung cancer crude incidence rate was 75.8/ 100000 in North Tees and 98.6/100 000 in Hartlepool, according to the local registry. ${ }^{16}$ These rates are consistent with the 85/100 000 rate reported in the present study which includes lung cancers pooled from North Tees and Hartlepool.
The 1995-9 male/female ratio for lung cancer was 1.33 and 1.49 in North Tees and Hartlepool respectively, ${ }^{16}$ reflected by the 1.33 male/female ratio in our study.

The Varese lung cancer registry data for 1993-7 indicate a histological confirmation rate of $87 \%,{ }^{19}$ similar to the $82 \%$ reported here.

The greatest possible care was taken to collect all cases of lung cancer; all the year 2000 files of all inpatient and outpatient departments at both Varese and Teesside were scrutinised. It is unlikely that the methodology we used excluded many patients with a clinical diagnosis only who were not referred. Indeed, the 72/100 000 crude incidence rate which we observed in Varese is even higher than the mean crude incidence rate of 67/100 000 recorded in the 1993-7 period in Varese. ${ }^{20}$

The unselected population of lung cancers accrued in this study in Teesside has epidemiological characteristics consistent with those reported in recent years by the NHS Northern and Yorkshire Cancer Registry and Information Service for the North Tees and Hartlepool areas ${ }^{1621}$-namely, a high

\begin{tabular}{|c|c|c|c|}
\hline & $p$ value & HR & $95 \% \mathrm{Cl}$ \\
\hline \multicolumn{4}{|l|}{ Univariate analysis } \\
\hline Age $(<65,65-75,75+$ years $) \dagger$ & 0.13 & 0.86 & 0.71 to 1.04 \\
\hline Sex $\ddagger$ & 0.18 & 1.28 & 0.89 to 1.84 \\
\hline Smoking habit (yes, no) & 0.22 & 1.19 & 0.90 to 1.56 \\
\hline Occupational risk (yes, no) & 0.10 & 1.33 & 0.94 to 1.88 \\
\hline Co-morbidity (yes, no) & 0.20 & 1.20 & 0.91 to 1.58 \\
\hline Asymptomatic diagnosis (yes, no) & $<0.0001$ & 0.38 & 0.26 to 0.56 \\
\hline Histology (NSCLC, SCLC, histologically unconfirmed lung cancer) & 0.012 & 0.81 & 0.68 to 0.95 \\
\hline NSCLC I-II (yes, no) & $<0.0001$ & 0.30 & 0.21 to 0.44 \\
\hline Active cancer treatment (yes, no) & $<0.0001$ & 0.48 & 0.36 to 0.66 \\
\hline Surgical resection (yes, no) & $<0.0001$ & 0.27 & 0.19 to 0.38 \\
\hline \multicolumn{4}{|l|}{ Multivariate analysis } \\
\hline Asymptomatic diagnosis (yes, no) & 0.045 & 0.65 & 0.43 to 0.99 \\
\hline NSCLC I-II (yes, no) & 0.057 & 0.63 & 0.39 to 1.01 \\
\hline Active cancer treatment (yes, no) & 0.11 & 0.77 & 0.56 to 1.06 \\
\hline Surgical resection (yes, no) & 0.0016 & 0.46 & 0.28 to 0.74 \\
\hline
\end{tabular}

$\dagger$ Age analysed as a trend through the three categories $(<65,65-75,75+$ years $)$.

¥Women $v$ men.

$\S p$ values for the predictors are the Wald statistics for the estimates in the model, conditional on the other predictors being present. 


\begin{tabular}{|c|c|c|c|c|}
\hline & Teesside† & Vareseł & $\chi^{2}$ & p value \\
\hline Advanced NSCLC: clinical stage III-IV & 103 (39\%) & $103(42 \%) \S$ & 0.44 & 0.507 \\
\hline $\begin{array}{l}\text { Co-morbidity in } \\
\text { NSCLC clinical stage I-II } \\
\text { NSCLC not staged } \\
\text { Lung cancer not histologically confirmed }\end{array}$ & $\begin{array}{l}17(7 \%) \\
4(2 \%) \\
74(28 \%)\end{array}$ & $\begin{array}{l}9(4 \%) \\
0(0 \%) \\
44(18 \%)\end{array}$ & 12.91 & $<0.001$ \\
\hline Histology: SCLC & $46(18 \%)$ & $28(12 \%)$ & 3.74 & 0.053 \\
\hline Total no of unresected cases & $244(93 \%)$ & $184(76 \%)$ & 29.64 & $<0.001$ \\
\hline \multicolumn{5}{|c|}{ 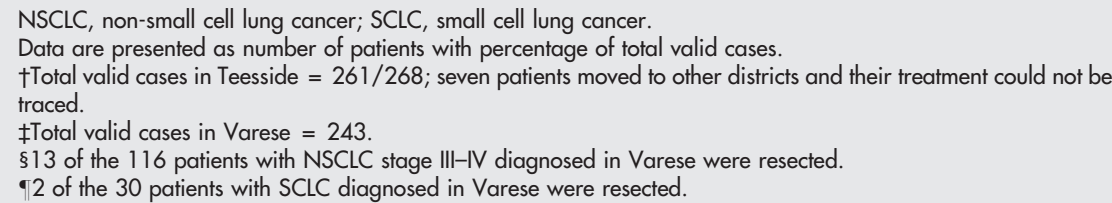 } \\
\hline
\end{tabular}

incidence of lung cancer (85/100 000); male/female ratio 1.33; elderly age; $72 \%$ histological confirmation rate (low by European and US standards); and a high prevalence of SCLC (24\%) among histologically confirmed cases. The Teesside cohort reported here therefore includes the full spectrum of unselected lung cancers that are commonly found in the north-east of the UK. Similarly, the unselected lung cancer patients from the Varese Province of Italy mirror the epidemiology reported by the Varese Cancer Registry in 1993-7 in that geographical area. ${ }^{19}$

This study shows several important differences between patients diagnosed with lung cancer in the two locations. In the Teesside area the age at diagnosis was higher and the proportion of women was significantly greater. The different sex distribution observed in our study reflects the national data reported by the WHO Databank and by Globocan. ${ }^{22}{ }^{23} \mathrm{UK}$ patients also had significantly more risk factors, higher comorbidity, lower $\mathrm{FEV}_{1}$, and poorer performance status.

This study shows that the patients in the UK and in Italy were referred in similar ways. However, the proportion of incidental diagnoses was significantly higher $(p<0.001)$ in the Varese area, a relevant finding since asymptomatic lung cancers incidentally detected are known to carry the best prognosis. $^{24}$

In Teesside we observed a significantly higher rate of cases diagnosed without pathological proof. This may be a reflection of more advanced disease due to aggressive tumour type, advanced age, and greater co-morbidity. It is noteworthy that, among histologically confirmed cases, in Teesside there was a significantly higher prevalence of large

Table 7 Patients with NSCLC stage I-II excluded from surgery in Teesside (20/37, 54\%) and in Varese (9/53, 17\%)

\begin{tabular}{|c|c|c|c|c|c|c|}
\hline No. & Sex & Age & $\begin{array}{l}\text { Clinical } \\
\text { stage }\end{array}$ & PS & Co-morbidity & Reason for inoperability \\
\hline \multicolumn{7}{|c|}{ Teesside patients } \\
\hline 1 & $\mathrm{~F}$ & 67 & IA & 3 & COPD, TIA, sigmoid cancer & Co-morbidity \\
\hline 2 & $M$ & 71 & IA & 0 & Angina pectoris & Co-morbidity \\
\hline 3 & $M$ & 68 & IA & 1 & COPD & Patient refusal \\
\hline 4 & $\mathrm{~F}$ & 45 & $\mathrm{IA}^{*}$ & 0 & None & * \\
\hline 5 & $M$ & 67 & IA & 2 & COPD & Co-morbidity \\
\hline 6 & $\mathrm{~F}$ & 70 & $\mathrm{IB}^{*}$ & 1 & None & * \\
\hline 7 & $\mathrm{~F}$ & 82 & $\mathrm{IB}$ & 3 & COPD, Crohn's disease, uterine cancer & Co-morbidity, age \\
\hline 8 & M & 52 & $\mathrm{IB}$ & 1 & COPD & Co-morbidity \\
\hline 9 & $M$ & 69 & IB & 2 & COPD & Co-morbidity \\
\hline 10 & $\mathrm{~F}$ & 68 & $\mathrm{IB}$ & 1 & Myocardial infarction & Co-morbidity \\
\hline 11 & $\mathrm{~F}$ & 72 & $\mathrm{IB}$ & 2 & COPD & Co-morbidity \\
\hline 12 & $\mathrm{~F}$ & 62 & $\| B$ & 1 & Angina pectoris & Co-morbidity \\
\hline 13 & $\mathrm{~F}$ & 70 & $\| B$ & 0 & COPD & Co-morbidity \\
\hline 14 & $\mathrm{~F}$ & 74 & $\| B$ & 3 & COPD & Co-morbidity \\
\hline 15 & $M$ & 73 & $\| B$ & 1 & Myocardial infarction, aortic stenosis & Co-morbidity \\
\hline 16 & $M$ & 78 & $\| \mathrm{B}$ & 1 & Myocardial infarction, TIA & Co-morbidity, age \\
\hline 17 & $\mathrm{~F}$ & 70 & $\| \mathrm{B}$ & 2 & COPD & Co-morbidity \\
\hline 18 & M & 68 & $\| \mathrm{B}$ & 1 & COPD, myocardial infarction, liver disease & Co-morbidity \\
\hline 19 & M & 77 & IIB & 2 & Myocardial infarction, angina pectoris & Co-morbidity, age \\
\hline 20 & $\mathrm{~F}$ & 56 & IIB & 1 & Cerebral stroke & Co-morbidity \\
\hline \multicolumn{7}{|c|}{ Varese patients } \\
\hline 1 & M & 77 & IB & 1 & Cardiac disease & Co-morbidity, age \\
\hline 2 & $M$ & 62 & $\mathrm{IB}$ & - & COPD & Co-morbidity \\
\hline 3 & $M$ & 72 & $\mathrm{IB}$ & 1 & COPD & Co-morbidity \\
\hline 4 & $\mathrm{~F}$ & 81 & $\mathrm{IB}$ & 1 & Diabetes, brain/cardiac vascular diseases & Co-morbidity, age \\
\hline 5 & M & 73 & IB & 3 & COPD & Co-morbidity \\
\hline 6 & $M$ & 74 & $\| B$ & 1 & Myocardial infarction & Co-morbidity \\
\hline 7 & $M$ & 68 & $\| B$ & 2 & Cardiac disease & Co-morbidity \\
\hline 8 & $M$ & 74 & $\| B$ & 1 & COPD & Co-morbidity \\
\hline 9 & $M$ & 78 & $\| B$ & - & Waldenstrom disease, diabetes & Co-morbidity, age \\
\hline
\end{tabular}

PS, WHO-ECOG performance status; COPD, chronic obstructive pulmonary disease; TIA, transient ischaemic attack. *Subsequently restaged as IIIA. 
cell carcinoma and of SCLC, two tumours with a relatively poor prognosis. While the median number of pack-years among ever smokers was similar in Teesside and in Varese (45.5 and 45.0, respectively), the significantly higher prevalence of cigarette smoking in Teesside might contribute to the higher proportion of SCLC detected. With regard to the relationship between sex and cigarette smoking, it is interesting to note that the prevalence of never smokers among men was similar in Varese and Teesside but there was a significantly higher prevalence of never smokers among women in Varese $(53 \%)$ compared with Teesside $(6 \%)$.

There are two major differences in the treatment modalities used in Teesside and Varese that reflect the lower chances of survival in the UK. The first is the more than threefold difference in the resection rate between Varese (24\%) and Teesside (7\%). This result confirms data of previous studies reporting overall lung cancer resection rates of about $10 \%$ in the UK, ${ }^{525} 26$ and is consistent with previous data from North Tees over a 3 year period (1997-9) when the overall resection rate was $11 \%{ }^{27}$ The second major difference is that $50 \%$ of the Teesside patients did not receive active cancer treatment compared with $25 \%$ in Varese. The fact that no explorative thoracotomies were performed in Teesside and Varese in 2000 may be accounted for by the small number of operations carried out overall (17 in Teesside and 59 in Varese).

While higher resection rates can be achieved in the UK (for example, by fast tracking patients), ${ }^{5}$ it is unclear if this leads directly to better survival. Co-morbidity was the main reason for inoperability. Moreover, almost a quarter of the UK patients had died within a month of presentation compared with only $7 \%$ of the Italians, a stark indication of the different type of patients in the two cohorts. Reasons that may explain the markedly worse health of the Teesside cohort include a higher rate of smokers and of occupational risk, delayed diagnosis, ${ }^{24}$ and more advanced stage of disease at presentation, reflected in our study by higher rate of clinical diagnoses only.

The apparently paradoxical finding of the univariate analysis that co-morbidity "protected" Teesside patients against the risk of death $(\mathrm{HR}=0.73)$ could be explained by the fact that the large majority of Teesside patients (73\%) had co-morbidities, including those patients who were successfully treated. Indeed, the multivariate analysis showed that the independent factors of survival in Teesside were surgical resection $(\mathrm{HR}=0.31)$ and active cancer treatment $(\mathrm{HR}=0.46)$.

The 3 year survival rate of $14 \%$ recorded in Varese is consistent with survival rates generally reported in Italy and in several other European countries, ${ }^{3}{ }^{4}$ and differs markedly from the 3 year survival rate of $7 \%$ we observed in Teesside. Interestingly, the latter survival rate is identical to that recorded in a national Scottish study in 1995, ${ }^{12}$ and reflects the low rate of survival in the overall population of patients with lung cancer in England and Wales in recent years. ${ }^{12}$ The striking difference in the initial part of the survival curves reflects the fact that the Teesside patients presented in poorer condition and with more advanced disease.

Cox's proportional hazard regression of 3 year mortality showed that surgical resection was the strongest multivariate predictor of survival in both the Varese and Teesside cohorts. In examining the main reasons for non-operability of lung cancer (advanced stage NSCLC, co-morbidity, aggressive histology), only co-morbidity differed significantly between Teesside and Varese, which is not surprising since it is a proxy for several risk factors. Radical surgical resection, the most important factor in long term survival, ${ }^{28-30}$ was precluded in the majority of Teesside patients.
The findings of this study support the concept that, in the year 2000, lung cancer patients in Teesside presented at a later stage, were rarely (7\%) asymptomatic, had more aggressive types of lung cancer and more co-morbidities. The combination of all these unfavourable factors seems to be responsible for the significantly lower chance of undergoing active and effective lung cancer treatment in Teesside than in Varese. Indeed, the rate of potentially operable cancers (NSCLC histology and stage I-II) was significantly lower in Teesside and, moreover, among the potentially operable patients the actual resection rate was significantly lower because of justifiable reasons including co-morbidity and poor performance status.

It must also be pointed out that socioeconomic status and other management factors such as delay in starting and/or carrying out treatment, which were not investigated in our study, may affect the survival of patients with lung cancer. $^{24}$

Importantly, the few patients from Teesside with NSCLC stage I-II who underwent resection had a 3 year survival rate of $59 \%$, which was not significantly different from the $45 \%$ survival rate observed in Varese. Cure rates will remain low unless a higher proportion of patients present and can be managed while still at stage I-II. ${ }^{24}$ Efforts should be increased to obtain an early diagnosis. It should be pointed out that the lung cancer screening programme in Varese contributed minimally to the overall number of lung cancers diagnosed in Varese in 2000 , with only 5/243 (2\%) of all lung cancers being detected by routine chest radiological screening. CT screening, which is currently proposed as a much more sensitive screening tool, ${ }^{31}$ would probably detect a greater proportion of asymptomatic lung cancers. However, there are no definitive conclusions about the potentially greater benefit of CT screening in reducing lung cancer mortality; ${ }^{29}{ }^{32}$ large randomised studies comparing CT screening with radiological screening are currently ongoing. ${ }^{33} 34$

The question remains whether the management of lung cancer is different because respiratory physicians in the UK manage patients differently from their colleagues in the EU and in the USA, or whether the presenting patient population is different either because patients present later or with more co-morbidity or, alternatively, that fewer asymptomatic patients are detected in the UK for whatever reasons. This study would suggest that lung cancer patients in the UK may well present at a later stage, often with additional comorbidity, poorer lung function, and poorer performance status. These factors are reflected by poorer rates of early survival, lower rates of radical treatment, and possibly a reduced rate of histological confirmation. When radical treatment is possible, however, survival rates are equivalent to those seen in Europe. The study would also suggest that, even when surgery might be possible, severe additional comorbidity and poor performance status limit operability more frequently in the UK than in Italy.

The situation can be improved in the UK. Public health education could promote the significance of warning symptoms in high risk groups. We should maintain an aggressive approach to co-morbidity-particularly maximising cardiorespiratory function-in patients in whom resection is otherwise feasible, and should promote surgery in "borderline" cases at the multidisciplinary team meetings. A reduction in smoking would clearly reduce the incidence of lung cancer, but would also preserve lung function in those in whom it had developed.

\section{ACKNOWLEDGEMENTS}

The authors thank P Alabardi, M Bandera, C Ballerio, J Brown, T Craig, O Ferrario, T Fitzpatrick, A Magli and E Vanetti for their assistance. 


\section{Authors' affiliations}

A Imperatori, F Rovera, G Dionigi, L Dominioni, Center for Thoracic Surgery, University of Insubria, Varese, Italy

R N Harrison, D N Leitch, P Sutton, Department of Respiratory Medicine, University Hospitals of North Tees and Hartlepool, North Tees and Hartlepool NHS Trust, Hardwick, Stockton on Tees TS19 8PE, UK G Lepore, Department of Respiratory Medicine, Ospedale S Antonio Abate, Gallarate, Italy

This study was supported by Provincia di Varese with a research scholarship to $\operatorname{Dr} A$ Imperatori and by research grants from COFIN 2002-2003 Ministero dell'Università e della Ricerca Scientifica, Italy and from Associazione PRE.DI.CA, Varese, Italy.

Competing interests: none declared.

The study sponsors had no involvement in the design of the study, the collection, analysis, and interpretation of data, in the writing of the report, or in the decision to submit the paper for publication. The authors are responsible for the research which they have designed and carried out, and for drafting and revising the submitted manuscript. All the authors have seen and approved the final version.

Al planned the analysis, collected data, interpreted data, and helped to write the report. DNL, GL, FR, GD and PS collected and helped to analyse data. RNH and LD planned the analysis, interpreted data and wrote the report.

\section{REFERENCES}

1 ONS. Report: Cancer survival in England and Wales, 1991-98. Health Statistics Quarterly 2000;6:71-80.

2 Coleman MP, Babb P, Sloggett A, et al. Socioeconomic inequalities in cancer survival in England and Wales. Cancer 2001;91:208-16.

3 Janssen-Heijnen MLG, Gatta G, Forman D, et al. Variation in survival of patients with lung cancer in Europe, 1985-1989. Eur J Cancer 1998;34:2191-6

4 Fry WA, Phillips JL, Menck HR. Ten-year survey of lung cancer treatment and survival in hospitals in the United States. Cancer 1999:86:1867-76.

5 Laroche $C$, Wells $F$, Coulden $R$, et al. Improving surgical resection rate in lung cancer. Thorax 1998;53:445-9.

6 Cartman ML, Hatfield AC, Muers MF, et al. Lung cancer: district active treatment rates affect survival. J Epidemiol Community Health 2002;56:424-9.

7 Damhuis RA, Schutte PR. Resection rates and postoperative mortality in 7,899 patients with lung cancer. Eur Respir J 1996;9:7-10.

8 Phillips A, Lawrence G, Laroche GM. Resection rates in lung cancer. Thorax 1999:54:374.

9 Dominioni L, Imperatori A, Rovera F, et al. Lung cancer screening in cigarette smokers in the province of Varese, Italy. Cancer 2000;89:2345-8.

10 Lung Cancer Working Party of the British Thoracic Society Standards of Care Committee. BTS recommendations to respiratory physicians for organising the care of patients with lung cancer. Thorax 1998;53:S1-8.

11 NHS Executive. Guidance on commissioning cancer services. Improving outcomes in lung cancer. London: Department of Health, 1998.
12 Gregor A, Thomson CS, Brewster DH, et al. Management and survival of patients with lung cancer in Scotland diagnosed in 1995: results of a national population based study. Thorax 2001;56:212-7.

13 Ahrens W, Merletti F. A standard tool for the analysis of occupational lung cancer in epidemiologic studies. Int J Occup Environ Health 1998:4:236-40.

14 Pollock AM, Vickers N. Deprivation and emergency admissions for cancers of colorectum, lung and breast in south east England: ecological study. BMJ 1998;317:245-52.

15 Mountain CF. Revision in the international system for staging lung cancer. Chest 1997; 111:1710-7.

16 Northern and Yorkshire Cancer Registry Information Service (NYCRIS). North Tees. Cancer registration and deaths, incidence and mortality rates, 1995-99, Available at http://www.nycris.org.uk.

17 Russo A, Crosignani P, Franceschi S, et al. Changes in lung cancer histological types in Varese Cancer Registry, Italy 1976-1992. Eur J Cancer 1997;33:1643-7.

18 Crosignani P, Piffer S. Respiratory tract cancers: lung and mesothelioma. Epidemiol Prev 2004;28:48-56.

19 Janssen-Heijnen MLG, Coebergh JWW. The changing epidemiology of lung cancer in Europe. Lung Cancer 2003;41:245-58.

20 Zanetti $\mathbf{R}$, Dafà $\mathrm{L}$, Pannelli $\mathrm{F}$, et al. Il cancro in Italia. Dati di incidenza dei Registri tumori 1993-98. Rome: II Pensiero Scientifico Editore, 2002:98-100.

21 Northern and Yorkshire Cancer Registry Information Service (NYCRIS). North Tees, Cancer registration and deaths, incidence and mortality rates 2000. Available at http://www.nycris.org.uk.

22 WHO Statistical Information System. WHO mortality databank, Available at http://www-depdb.iarc.fr/who/who.htm and http://www.who.int/whosis/.

23 Ferlay J, Bray F, Pisani P, et al. GLOBOCAN 2000: cancer incidence, mortality and prevalence worldwide, Version 1.0.IARC CancerBase No 5. Lyon: IARC Press, 2001

24 Moody A, Muers M, Forman D. Delays in managing lung cancer. Thorax 2004;59:1-3.

25 British Thoracic Socierty and Society of Cardiothoracic Surgeons of Great Britain and Ireland Working Party. Guidelines on selection of patients with lung cancer for surgery. Thorax 2001;56:89-108.

26 Society of Cardiothoracic Surgeons of Great Britain and Ireland. Report BTSSCTS, 2002. Available at www. scts.org.

27 Leitch DN, Forrest IA, Harrison JS, et al. All cases of lung cancer presenting to a non-teaching urban UK district general hospital 1997 to 1999. Eur Respir J 2000;16:362S

28 Goldstraw P. Surgical oncologic principles. Chest Surg Clin North Am 2001;11:1-16.

29 Strauss GM. The Mayo Lung Cohort: a regression analysis focusing on lung cancer incidence and mortality. J Clin Oncol 2002;20:1973-83.

30 Hoffman PC, Manuer AM, Vokes EE. Lung cancer. Lancet 2000;355:479-85.

31 Henschke Cl, Shaham D, Yankelevitz DF, et al. CT screening for lung cancer: past and ongoing studies. Semin Thorac Cardiovasc Surg 2005; 17:99-106.

32 Strauss GM, Dominioni L, Jett JR, et al. Como International Conference Position Statement. Lung cancer screening for early diagnosis 5 years after the 1998 Varese Conference. Chest 2005;127:1146-51.

33 Church T, National Lung Screening Trial Executive Committee. Chest radiography as the comparison intervention for spiral CT in the National Lung Screening Trial. Acad Radiol 2003; 10:713-5.

34 Gohagan J, Marcus P, Fagerstrom R, et al. Baseline findings of a randomized feasibility trial of lung cancer screening with spiral CT scan vs chest radiograph. Chest 2004; 126:114-21. 